\title{
Liability to diseases and their relation to dry matter intake and energy balance in German Holstein and Fleckvieh dairy cows
}

\author{
V. A. E. Becker, ${ }^{1 *}$ (으 E. Stamer, ${ }^{2}$ and G. Thaller ${ }^{1}$ \\ ${ }^{1}$ Institute of Animal Breeding and Husbandry, Christian-Albrechts-University, 24098 Kiel, Germany \\ ${ }^{2} \mathrm{TiDa}$ Tier und Daten GmbH, 24259 Westensee/Brux, Germany
}

\begin{abstract}
Dairy cow efficiency is increasingly important for future breeding decisions. The efficiency is determined mostly by dry matter intake (DMI). Reducing DMI seems to increase efficiency if milk yield remains the same, but resulting negative energy balance (EB) may cause health problems, especially in early lactation. Objectives of this study were to examine relationships between DMI and liability to diseases. Therefore, cow effects for DMI and EB were correlated with cow effects for 4 disease categories throughout lactation. Disease categories were mastitis, claw and leg diseases, metabolic diseases, and all diseases. In addition, this study presents relative percentages of diseased cows per days in milk (DIM), repeatability, and cow effect correlations for disease categories across DIM. A total of 1,370 German Holstein (GH) and 287 Fleckvieh (FV) primiparous and multiparous dairy cows from 12 dairy research farms in Germany were observed over a period of 2 yr. Farm staff and veterinarians recorded health data. We modeled health and production data with threshold random regression models and linear random regression models. From DIM 2 to 305 average daily DMI was $22.1 \mathrm{~kg} / \mathrm{d}$ in GH and $20.2 \mathrm{~kg} / \mathrm{d}$ in FV. Average weekly $\mathrm{EB}$ was $2.8 \mathrm{MJ}$ of $\mathrm{NE}_{\mathrm{L}} / \mathrm{d}$ in $\mathrm{GH}$ and 0.6 MJ of $\mathrm{NE}_{\mathrm{L}} / \mathrm{d}$ in FV. Most diseases occurred in the first 20 DIM. Multiparous cows were more susceptible to diseases than primiparous cows. Relative percentages of diseased cows were highest for claw and leg diseases, followed by metabolic diseases and mastitis. Repeatability of disease categories and production traits was moderate to high. Cow effect correlations for disease categories were higher for adjacent lactation stages than for more distant lactation stages. Pearson correlation coefficients between cow effects for DMI, as well
\end{abstract}

Received March 23, 2020.

Accepted August 25, 2020.

*Corresponding author: vbecker@tierzucht.uni-kiel.de as EB, and disease categories were estimated from DIM 2 to 305. Almost all correlations were negative in $\mathrm{GH}$, especially in early lactation. In FV, the course of correlations was similar to $\mathrm{GH}$, but correlations were mostly more negative in early lactation. For the first 20 DIM, correlations ranged from -0.31 to 0.00 in $\mathrm{GH}$ and from -0.42 to -0.01 in FV. The results illustrate that future breeding for dairy cow efficiency should focus on DMI and EB in early lactation to avoid health problems.

Key words: dairy cow, dry matter intake, energy balance, feed efficiency, health

\section{INTRODUCTION}

Improving dairy cow efficiency has been investigated for many decades (Sauvant, 2019), but it has become a hot topic in recent years. In part, this is owed to feed costs accounting for about $50 \%$ of total milk production costs (Hemme et al., 2014), limited resources such as land or water, and society's demand to reduce the negative environmental effect of dairy production (Boichard and Brochard, 2012).

Dairy cow efficiency during lactation is affected by numerous complex processes. Consequently, it is difficult to define efficiency precisely (Berry and Crowley, 2013; Veerkamp et al., 2013; VandeHaar et al., 2016). In the past, dairy cow breeding programs improved feed efficiency, diluting maintenance through selecting cows with higher milk yield; possibilities for further progress, however, have become limited (VandeHaar et al., 2016). Milk yield and feed intake are correlated positively. Nevertheless, cows cannot cover their nutrient demand by their feed intake (Van Arendonk et al., 1991). Breeding for milk yield led to a stronger negative energy balance (EB), especially in early lactation (Rauw et al., 1998). The intensity of negative EB is genetically driven and cannot be compensated with higher energy content in feed (Friggens et al., 2007). Cows use body reserves to balance the need for energy (Goff and Horst, 1997). During negative EB, cows are under metabolic stress, which in turn induces an immunosuppression. Furthermore, this leads to a higher liability to diseases 
such as mastitis, claw and leg diseases, or metabolic diseases (Goff and Horst, 1997; Collard et al., 2000; Esposito et al., 2014).

For quite some time researchers have been using ratio or residual traits to estimate dairy cow efficiency indirectly (Berry and Crowley, 2013). Ledinek et al. (2019) concluded that breeding for ratio traits, such as BW efficiency, feed efficiency, and energy efficiency, lead to a stronger body tissue mobilization, as well as a longer and more intense negative EB in early lactation. Residual energy intake has been favored as a trait definition, based on the assumption that more efficient cows have a lower energy intake than would be expected for their energy demand. Efficient cows are characterized by a negative residual energy intake (Connor, 2015). Hurley et al. (2018) showed that residual energy intake and EB have a strong phenotypic correlation (Pearson correlation coefficient from 0.81 to 0.94 ). This agrees with Veerkamp (1998), who suggested that this trait seems to measure EB indirectly. Breeding for efficiency using only such traits has to be regarded with caution because an increase of negative EB should be avoided, especially in early lactation (Rauw et al., 1998; Spurlock et al., 2012).

For evaluating meaningful efficiency traits, it is important to investigate the trait DMI, because individual DMI is a key factor for estimating efficiency. Some researchers recommend selection against DMI to improve efficiency if other traits such as health or fertility are not affected negatively (VandeHaar et al., 2016). However, reducing DMI could decrease EB, and a negative EB increases the liability to diseases (Rauw et al., 1998). There is little knowledge about phenotypic and genetic relationships between liability to diseases and DMI as the recording of feed intake and an accurate recording of diseases is expensive, and furthermore, a joint analysis of both data types is not trivial (Veerkamp, 1998; Neuenschwander et al., 2012; VandeHaar et al., 2016). Nevertheless, this knowledge is essential to decide whether breeding for higher or lower DMI during certain lactation stages is beneficial. In the future, genomic selection may enable the integration of breeding values for DMI or EB in the breeding goal (Berry and Pryce, 2014; de Haas et al., 2015; Harder et al., 2019), and this could contribute to breeding for dairy cow efficiency.

The aim of this study was to provide first insights into the genetic relationships between diseases and DMI, as well as EB, using phenotypic longitudinal data. On the one hand, this study presents relative percentages of diseased cows per DIM, repeatability of disease categories, DMI, feed energy intake (FEI), ECM yield, and $\mathrm{EB}$, as well as cow effect correlations for disease categories across DIM. On the other hand, this study illustrates correlations between cow effects for disease categories estimated with threshold random regression models and cow effects for DMI, ECM yield, and EB estimated with linear random regression models.

\section{MATERIALS AND METHODS}

\section{Health Data}

This study was based on health data from 1,370 German Holstein $(\mathbf{G H})$ and 287 Fleckvieh $(\mathbf{F V})$ dairy cows from $8 \mathrm{GH}$ and $4 \mathrm{FV}$ dairy research farms in Germany. Fleckvieh represents a dual-purpose breed mainly found in southern Germany. All cows were housed in a freestall barn. Data were collected during farm-specific feeding trials of different lengths between September 2014 and March 2017. The number of observed cows per farm ranged from 30 to 349 for $\mathrm{GH}$ and from 59 to 97 for FV. Farm staff and veterinarians recorded health data. We standardized the data according to the central key for health data recording. This central key defines diagnoses, measures, and findings, as well as their documentation, to enable evaluations of health data in Germany (GKUH, 2019). Undefined health data were discarded. Following a plausibility check, we eliminated records of milk fever and retained placenta after DIM 14. Except for mastitis, health data were aggregated to 7 disease categories because of too low frequencies of single diseases for reasonable analyses. Furthermore, all recorded health data of the 7 disease categories and mastitis were grouped into the category all diseases to define a category for general health (Table 1). Our analyses contain 4 most important disease categories: mastitis (MAST), claw and leg diseases (CLAW), metabolic diseases (METAB), and all diseases (ALLDIS). In GH and FV, 33 and $21 \%$ of ALLDIS were MAST, 27 and $37 \%$ were CLAW, and 12 and $20 \%$ were METAB, respectively.

Binary Coding. Health data recording on the research farms differed, with some farms recording first treatment only and others recording every treatment during a disease period. Therefore, we chose 6 farms with 747 cows and 222,456 records that recorded every treatment to calculate average treatment days for each disease category. Each daily observation was assigned a disease code ( 0 or 1$)$ to express disease categories as binary traits. First treatment day, followed by calculated average treatment days and sick days, were coded as 1 to classify days of a disease period. Sick days have been added to consider that some diseases affect a cow for longer than the treatment days (Buttchereit et al., 2012). According to Buttchereit et al. (2012), sick days 
Table 1. Health data and disease categories

\begin{tabular}{|c|c|c|}
\hline Disease category & Abbreviation & Health data \\
\hline Other udder diseases & & Udder edema, injuries, other \\
\hline Metabolic diseases & METAB & Milk fever, ketosis, acidosis, abomasal displacement, other \\
\hline Reproduction disorders & & Metritis, retained placenta, disturbances of the estrus cycle, other \\
\hline Other diseases & & Pain, fever, peritonitis, fistula, anorexia, other \\
\hline All diseases & ALLDIS & All health data \\
\hline
\end{tabular}

were $5 \mathrm{~d}$ for MAST and $8 \mathrm{~d}$ for CLAW and METAB. The beginning of a new disease period was assumed if a treatment of a specific disease category was after the previous disease period. All other days were coded as 0 to classify these days as healthy.

Descriptive Statistics. For the disease categories MAST, CLAW, and ALLDIS, health data from calving to 305 DIM were analyzed. For METAB the first 76 DIM in GH and the first 62 DIM in FV were included because METAB hardly occurred afterward. Average observation days per cow and number of cows within lactations for each disease category are presented in Table 2. Number of affected cow days, as well as cows and lactations with at least 1 treatment, are illustrated in Table 3. We calculated the percentage of treated cows based on their total observation days. Observation days per cow varied largely because data recording only took place during farm-specific feeding trials, and some cows dropped out of a trial prematurely. Data from only 3 farms could be used for METAB in FV. One farm had no METAB because health data recording started after 39 DIM. Depending on disease category, 1.7 to $7.2 \%$ of cow days in $\mathrm{GH}$ and 1.1 to $5.4 \%$ of cow days in FV were classified as diseased (Table 3 ).

Model Fitting. Threshold models are theoretically superior to linear models to analyze binary coded disease categories (Gianola, 1982). They assume that the observed variable (the binary code 0 or 1 ) depends on an underlying, unobservable, continuous variable that is normally distributed and called liability. If the liability is below a fixed threshold, the observed variable takes a certain phenotype (e.g., healthy, coded with 0 ) and otherwise it takes the other phenotype (e.g., diseased, coded with 1; Gianola, 1982; Moreno et al., 1997; Neuenschwander et al., 2012). Random regression test-day models take into account heterogenic variance of cow effects; they are usually used to analyze longitudinal data (Swalve, 2000; Schaeffer, 2004). Therefore, we used the random regression methodology to analyze cow effects for disease categories, DMI, FEI, ECM yield, and EB in the course of lactations and to evaluate changing correlations between energetic status and cows' ability to fight against pathogens (Carlén et al., 2009; Buttchereit et al., 2012).

Model fitting of the threshold random regression models started with an extreme category analysis of all fixed effects (Harville and Mee, 1984). To avoid the extreme category problem, herd-year classes containing a single value (0 or 1 ) were combined with neighboring classes (Luo et al., 2001). As random regression coefficients, we chose normalized Legendre polynomials, which estimate covariance between records of the same cow and describe the shape of cow-specific lactation curves (Kirkpatrick et al., 1990). Standardized DIM (sDIM) was computed as $\mathrm{sDIM}=-1+2(\mathrm{DIM}-$ $\left.\mathrm{DIM}_{\min }\right) /\left(\mathrm{DIM}_{\max }-\mathrm{DIM}_{\min }\right)$ (Schaeffer, 2004), where

Table 2. Number of cows within lactation and average observation days per cow (mean \pm SD) for 4 disease categories in German Holstein and Fleckvieh dairy cows

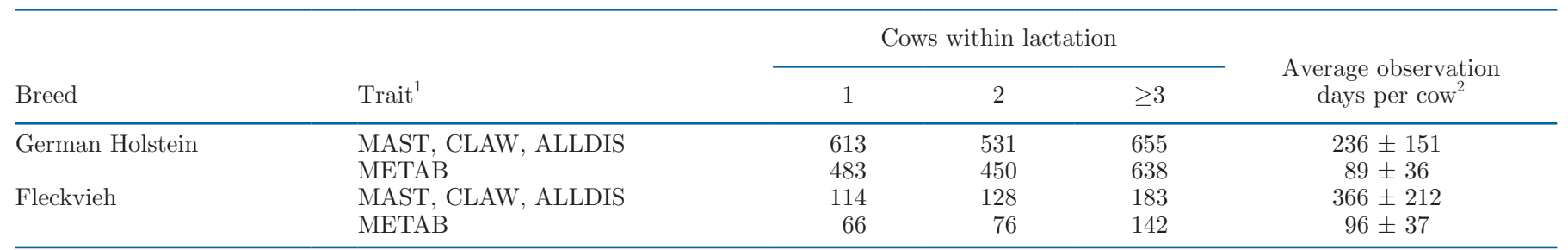

${ }^{1}$ MAST $=$ mastitis, CLAW $=$ claw and leg diseases, METAB $=$ metabolic diseases, ALLDIS $=$ all diseases.

${ }^{2}$ Calculation based on total observation days across lactations. 
Table 3. Percentage of affected cow days as well as cows and lactations with at least 1 treatment for 4 disease categories in German Holstein and Fleckvieh dairy cows

\begin{tabular}{|c|c|c|c|c|c|c|}
\hline Breed & $\begin{array}{l}\text { Disease } \\
\text { category }^{1}\end{array}$ & $\begin{array}{l}\text { Lactation } \\
\text { stage (d) }\end{array}$ & \multicolumn{2}{|c|}{ Cow days } & \multicolumn{2}{|c|}{ Cows (lactations) } \\
\hline \multirow{2}{*}{ German Holstein } & METAB & $1-76$ & 118,311 & 3.1 & $1,335(1,749)$ & $20.8(17.6)$ \\
\hline & ALLDIS & $1-305$ & 323,666 & 7.2 & $1,370(2,075)$ & $75.7(62.6)$ \\
\hline \multirow[t]{2}{*}{ Fleckvieh } & MAST & $1-305$ & 105,183 & 1.1 & $287(557)$ & $29.6(18.1)$ \\
\hline & ALLDIS & $1-305$ & 105,183 & 5.4 & $287(557)$ & $71.1(60.5)$ \\
\hline
\end{tabular}

${ }^{1}$ MAST $=$ mastitis, CLAW $=$ claw and leg diseases, METAB $=$ metabolic diseases, ALLDIS $=$ all diseases.

${ }^{2}$ Only 3 farms.

$\mathrm{DIM}_{\min }$ and $\mathrm{DIM}_{\max }$ are the minimum and maximum value of DIM $\left(\mathrm{DIM}_{\min }=1, \mathrm{DIM}_{\max }=305\right.$ or 76 or 62$)$. Legendre polynomials of second degree were calculated with the function terms $\mathrm{x}_{0}=1, \mathrm{x}_{1}=\mathrm{sDIM}$, and $\mathrm{x}_{2}=$ $0.5\left(3 \mathrm{sDIM}^{2}-1\right)$. Legendre polynomials of third degree were computed with $\mathrm{x}_{0}, \mathrm{x}_{1}, \mathrm{x}_{2}$, and $\mathrm{x}_{3}=0.5\left(5 \mathrm{sDIM}^{3}\right.$ $-3 \mathrm{sDIM})$. The function terms $\mathrm{x}_{0}, \mathrm{x}_{1}, \mathrm{x}_{2}, \mathrm{x}_{3}$, and $\mathrm{x}_{4}=$ $0.125\left(35 \mathrm{sDIM}^{4}-30 \mathrm{sDIM}^{2}+3\right)$ were used to calculate Legendre polynomials of fourth degree. The GLIMMIX procedure in SAS 9.4 does not determine information criteria for models based on pseudo-likelihood (SAS Institute Inc., 2013). Consequently, model fit could not be evaluated by information criteria. Therefore, our model evaluation criteria were achieved convergence, fixed effects' significance, and dispersion parameter.

Statistical Analyses. The liabilities to disease categories were modeled with the following threshold random regression model:

$$
\mathrm{E}\left[\pi_{i j k l}\right]=\Phi\left(\mathrm{HY}_{i}+\mathrm{LNO}_{j}+\mathrm{DAY}_{k}+\sum_{n=1}^{4} \operatorname{cow}_{l n} \times \mathrm{lp}_{l n}\right),
$$

where $\mathrm{E}\left[\pi_{i j k l}\right]$ is the expected probability for occurrence of disease category; $\Phi$ is the cumulative probability function of standard normal distribution as probit link function; $\mathrm{HY}_{i}$ is the fixed effect of the $i$ th herd-year ( $i$ $=1$ to 20 and 1 to 8 for MAST, CLAW, and ALLDIS in $\mathrm{GH}$ and $\mathrm{FV} ; i=1$ to 16 for METAB in GH; $i=$ the fixed effect of the $i$ th year with 1 to 4 for METAB in $\mathrm{FV}) ; \mathrm{LNO}_{j}$ is the fixed effect of the $j$ th lactation $(j=1$, $2, \geq 3$ for MAST, CLAW, METAB, and ALLDIS; $j=1$, $\geq 2$ for METAB in FV); $\mathrm{DAY}_{k}$ is the fixed effect of the $k$ th DIM, DIM 1 to 10 separated then in 5-d intervals $(k=1$ to 69 for MAST, CLAW, and ALLDIS in GH and FV; $k=1$ to 24 and 1 to 21 for METAB in GH and $\mathrm{FV}) ; \mathrm{cow}_{l n}$ is the $n$th random regression coefficient of the $l$ th cow $(l=1$ to 1,370 and 1 to 287 for MAST,
CLAW, and ALLDIS in GH and FV; $l=1$ to 1,335 and 1 to 212 for METAB in $\mathrm{GH}$ and $\mathrm{FV}$ ); $\operatorname{lp}_{l n}$ is the $n$th term of the third-degree Legendre polynomial function for DIM of the lth cow. We analyzed the threshold random regression models with the procedure GLIMMIX and the residual marginal pseudo-likelihood (RMPL) method in SAS 9.4 (SAS Institute Inc., 2013). An unstructured covariance matrix was used for the random cow effect. The significance of differences between least squared means of lactations was adjusted with Bonferroni correction. Repeatability was estimated on the underlying link scale from DIM 1 to 305 within breed using estimated regression coefficients according to Nakagawa and Schielzeth (2010). Cow effect correlations within disease category were computed between selected DIM points separated by regular intervals of $30 \mathrm{~d}$. For METAB, the intervals comprise $10 \mathrm{~d}$.

\section{Production Data}

Data for individual daily DMI, FEI, ECM yield, and weekly EB were available for 1,340 and 287 of GH and FV dairy cows with health data, respectively. Individual feed intake per day was measured via single feeding troughs equipped with a weighing unit and automatic cow identification. All cows were fed ad libitum with partial mixed rations and separate concentrates or TMR. Data of ration components, DM, energy contents (in MJ of $\mathrm{NE}_{\mathrm{L}}$ ), and concentrate types were recorded regularly. Net energy of lactation is defined as the energy amount in feed that is available for milk production and body maintenance (Kirchgeßner et al., 2014). Daily milk yield records are based on at least 2 milkings. One research farm used an automatic milking system, so data were recorded for $24 \mathrm{~h}$. Milk ingredients were measured once a week, thus we calculated ECM yield for $1 \mathrm{~d}$ /wk according to Kirchgeßner et al. (2014): 
Table 4. Number of cows within lactation and average DIM per cow for DMI, feed energy intake (FEI), ECM yield, and energy balance (EB) in German Holstein and Fleckvieh dairy cows

\begin{tabular}{|c|c|c|c|c|c|c|}
\hline \multirow[b]{2}{*}{ Breed } & \multirow[b]{2}{*}{ Trait } & \multicolumn{4}{|c|}{ Cows within lactation } & \multirow{2}{*}{$\begin{array}{l}\text { Average DIM } \\
\text { per cow }{ }^{1}\end{array}$} \\
\hline & & 1 & 2 & 3 & $\geq 4$ & \\
\hline German Holstein & $\mathrm{EB}$ & 543 & 499 & 362 & 380 & 121 \\
\hline \multirow[t]{2}{*}{ Fleckvieh } & DMI, FEI, ECM yield & 114 & 128 & 119 & 120 & 151 \\
\hline & $\mathrm{EB}$ & 114 & 128 & 119 & 120 & 149 \\
\hline
\end{tabular}

${ }^{1}$ Calculation based on total observation days across lactations.

$$
\begin{gathered}
\text { ECM yield }(\mathrm{kg} / \mathrm{d})=\text { milk yield }(\mathrm{kg} / \mathrm{d}) \\
\times[0.39 \times \text { milk fat }(\%)+0.24 \times \text { milk protein }(\%) \\
+0.17 \times \text { milk lactose }(\%)] / 3.17 .
\end{gathered}
$$

Average weekly EB (in MJ of $\mathrm{NE}_{\mathrm{L}}$ ) based on calendar weeks was computed as difference between energy intake and energy requirements. The FEI was calculated by multiplying DMI with feed's energy content. Estimated energy amount for maintenance, milk production, growth, and gestation were considered as energy requirements. Detailed formulas can be taken from Harder et al. (2019).

Descriptive Statistics. Lactation stage for statistical analyses were defined from DIM 2 to 305. Day of calving were excluded because of incomplete measurements. In addition, we eliminated observations of DMI, FEI, milk yield, milk ingredients, and EB exceeding the range of \pm 4 standard deviations of the mean value. Number of cows within lactations and average DIM per cow are illustrated in Table 4. Descriptive statistics of the production traits are presented in Table 5. Mean values were higher in $\mathrm{GH}$ compared with $\mathrm{FV}$ : for DMI $+1.9 \mathrm{~kg} / \mathrm{d}$, for ECM yield $+6.1 \mathrm{~kg} / \mathrm{d}$, and for EB +2.2 MJ of $\mathrm{NE}_{\mathrm{L}} / \mathrm{d}$ (Table 5).

Model Fitting. In the first step of model fitting, we tested the effect of feeding group within farm. Therefore, we used mixed models including the fixed effects herd-test-week, feeding group, lactation, DIM within lactation according to Ali and Schaeffer (1987), and a random cow effect. Ali and Schaeffer function was calculated with the terms $\mathrm{x}_{1}=\mathrm{DIM} / 305, \mathrm{x}_{2}=$ $(\mathrm{DIM} / 305)^{2}, \quad \mathrm{x}_{3}=\ln (305 / \mathrm{DIM})$, and $\mathrm{x}_{4}=[\ln (305 /$ $\mathrm{DIM})]^{2}$. The analyses were computed in SAS 9.4 using the procedure MIXED and the residual (restricted) maximum likelihood (REML) method (SAS Institute Inc., 2013). Subsequently, we extended the effect of herd-test-week to a herd-group-test-week in cases of significant group differences. This effect had to contain at least 3 observations; otherwise, the effect class was combined with a neighboring herd-test-week.

In the second step of model fitting, we compared 3 parametric functions to model fixed lactation curves within lactation: Ali and Schaeffer function (Ali and Schaeffer, 1987) and Legendre polynomials of third and fourth degree. Furthermore, we varied the fixed effect of lactation between 3 and 4 classes. Analyses were done with the procedure MIXED and the maximum likelihood (ML) method in SAS 9.4 (SAS Institute Inc., 2013). Goodness of fit was evaluated using Akaike information criterion (AICC; Burnham and Anderson, 1998) and Bayesian information criterion (BIC; Schwarz, 1978). The model that minimizes AICC or $\mathrm{BIC}$ is superior, but if values of AICC or BIC are similar, the simpler model is generally considered preferable (Littell et al., 2006).

Afterward we chose the best fitting fixed effects model for the third step of model fitting. Therefore, we

\begin{tabular}{|c|c|c|c|c|c|}
\hline Breed & Trait & Unit & No. & Mean & SD \\
\hline German Holstein & FEI & $\mathrm{MJ}$ of $\mathrm{NE}_{\mathrm{L}} / \mathrm{d}$ & 240,564 & 155.6 & 34.92 \\
\hline \multirow[t]{3}{*}{ Fleckvieh } & DMI & $\mathrm{kg} / \mathrm{d}$ & 103,082 & 20.2 & 3.95 \\
\hline & FEI & MJ of $\mathrm{NE}_{\mathrm{L}} / \mathrm{d}$ & 103,080 & 136.8 & 28.48 \\
\hline & ECM yield & $\mathrm{kg} / \mathrm{d}$ & 14,034 & 28.9 & 7.55 \\
\hline
\end{tabular}

Table 5. Descriptive statistics of DMI, feed energy intake (FEI), ECM yield, and energy balance (EB) in German Holstein and Fleckvieh dairy cows (DIM 2-305) 
compared functions for the random cow effect modeled with Legendre polynomials of second to fourth degree.

Statistical Analyses. The following best fitting linear random regression model was used for statistical analyses of DMI, FEI, ECM yield, and EB:

$$
\begin{gathered}
y_{i j k l}=\mu+\mathrm{HTW}_{i}+\mathrm{LNO}_{j}+\sum_{n=1}^{4} \mathrm{C}_{j n} \\
\times \mathrm{as}_{j n}+\sum_{n=1}^{5} \operatorname{cow}_{k n} \times \operatorname{lp}_{k n}+\mathrm{e}_{i j k l},
\end{gathered}
$$

where $y_{i j k l}$ is the observation of DMI, FEI, ECM yield, or EB; $\mu$ is the overall mean; $\mathrm{HTW}_{i}$ is the fixed effect of the $i$ th herd-test-week $(i=1$ to 812 and 1 to 940 for DMI and FEI in GH and FV; $i=1$ to 762 and 1 to 882 for $\mathrm{ECM}$ yield in $\mathrm{GH}$ and $\mathrm{FV} ; i=1$ to 1,119 and 1 to 852 for $\mathrm{EB}$ in $\mathrm{GH}$ and $\mathrm{FV}$ ); $\mathrm{LNO}_{j}$ is the fixed effect of the $j$ th lactation $(j=1,2,3, \geq 4) ; \mathrm{C}_{j n}$ is the $n$th fixed regression coefficient within the $j$ th lactation; $\mathrm{as}_{j n}$ is the $n$th term of the Ali and Schaeffer function for DIM within the $j$ th lactation; $\operatorname{cow}_{k n}$ is the $n$th random regression coefficient of the $k$ th cow $(k=1$ to 1,340 and 1 to 287 for DMI and FEI in GH and FV; $k=$ 1 to 1,336 and 1 to 286 for ECM yield in GH and $\mathrm{FV} ; k=1$ to 1,321 and 1 to 286 for $\mathrm{EB}$ in $\mathrm{GH}$ and $\mathrm{FV}) ; \operatorname{lp}_{k n}$ is the $n$th term of the fourth-degree Legendre polynomial function for DIM of the $k$ th cow; and $\mathrm{e}_{i j k l}$ is the random residual error. The linear random regression models were analyzed with the procedure MIXED and the method REML in SAS 9.4 (SAS Institute Inc., 2013). An unstructured covariance matrix was used for the random cow effect. Repeatability of the production traits was estimated using Legendre polynomials, estimated regression coefficients, and the formula according to Nakagawa and Schielzeth (2010):

$$
\mathrm{R}=\frac{\sigma_{\mathrm{c}}^{2}}{\sigma_{\mathrm{c}}^{2}+\sigma_{\mathrm{r}}^{2}},
$$

where $\sigma_{\mathrm{c}}^{2}$ is the between-cow variance, $\sigma_{\mathrm{r}}^{2}$ is the withincow variance or rather the residual variance, and the sum of $\sigma_{\mathrm{c}}^{2}$ and $\sigma_{\mathrm{r}}^{2}$ is the total phenotypic variance.

\section{Correlations Between Cow Effects}

Subsequently, we estimated Pearson correlation coefficients between cow effects for the 4 disease categories and DMI, FEI, ECM yield, as well as EB, from DIM 2 to 305 . Therefore, we used the procedure CORR in SAS 9.4 (SAS Institute Inc., 2013). The estimated correlations included only cows with at least 10 observations for health and production data (DMI, FEI, and ECM yield). For EB cows should have at least 2 observations. Standard error for each correlation coefficient was estimated from the $95 \%$ confidence interval that was calculated in SAS 9.4 (SAS Institute Inc., 2013).

\section{RESULTS}

Frequencies of lactations with at least 1 treatment were highest for ALLDIS with $62.6 \%$ in GH and $60.5 \%$ in $\mathrm{FV}$, followed by CLAW with $34.9 \%$ in GH and $40.9 \%$ in $\mathrm{FV}$ and MAST with $21.7 \%$ in $\mathrm{GH}$ and $18.1 \%$ in FV. For METAB frequencies of treated lactations were $17.6 \%$ in GH and $16.2 \%$ in FV (Table 3 ).

Relative percentages of diseased cows showed pronounced peaks within the first 20 DIM for both breeds, except for CLAW in GH and MAST in FV. In the further course of lactation, relative percentages of diseased cows decreased to an almost constant category specific level. For CLAW in GH and MAST in FV, relative percentages of diseased cows were almost constant throughout lactation (Figures 1 and 2).

Relative percentages of diseased cows increased with higher lactations (Table 6). This could be observed clearly for ALLDIS. In GH and FV, relative percentage of diseased cows for ALLDIS increased from 0.052 and 0.046 in first lactation to 0.083 and 0.068 in lactation $\geq 3$. Least squares means between lactations differed ( $P$ $<0.001$ to $P<0.05)$ with few exceptions, especially for CLAW in GH.

Fixed effects (herd-year, lactation, DIM) included in the threshold random regression models affected $(P<$ $0.001)$ the incidence of each disease category, except lactation for CLAW in GH $(P=0.23)$. The dispersion parameters were between 0.45 and 0.92 .

Figure 3 shows disease categories' repeatability in the course of lactation. Repeatability ranged for both breeds for MAST from 0.60 to 0.99, for CLAW from 0.39 to 0.94 , and for ALLDIS from 0.28 to 0.95 . Repeatability for METAB was highest with a range from 0.78 to 0.99. Figure 4 presents repeatability for DMI, FEI, ECM yield, and EB in GH and FV. For DMI and FEI repeatability varied between 0.33 and 0.70 in $\mathrm{GH}$ and FV. Repeatability for ECM yield was in a range from 0.61 to 0.81 , and repeatability for EB varied between 0.50 and 0.85 for both breeds. Analogous to disease categories, highest repeatability could be observed in early and late lactation for production traits.

Table 7 and 8 provide correlations between cow effects of selected DIM for ALLDIS and METAB in GH (above the diagonal) and FV (below the diagonal). Correlations for MAST and CLAW showed the same pattern (data not shown). Generally, adjacent lactation 
stages were higher correlated than more distant lactation stages.

In GH, all Pearson correlation coefficients between cow effects for DMI and disease categories were negative (Figure 5). This could not be observed for FV because correlations became positive in late lactation (Figure 6). Pearson correlation coefficients were lowest for almost all disease categories up to DIM 40 for both breeds; values were between -0.42 and -0.03 . ALLDIS were correlated with DMI most negatively in early lactation. In $\mathrm{GH}$, all correlations differed from 0 $(P<0.05)$ up to DIM 53. In FV, correlations between METAB and DMI differed from $0(P<0.05)$ up to DIM 44; up to DIM 26 and 38, correlations between CLAW as well as ALLDIS and DMI differed from $0(P$ $<0.05$ ); correlations between MAST and DMI differed not significantly from 0 . Pearson correlation coefficients between cow effects for FEI and disease categories were similar (data not shown).

Pearson correlation coefficients between cow effects for ECM yield and disease categories ranged from -0.12 to 0.16 in FV; values were mostly positive. They differed not significantly from 0 . In GH, correlations varied between -0.14 and 0.03 ; values were mostly negative but not significant. For MAST correlations differed from $0(P<0.05)$ up to DIM 28 and for CLAW after DIM 247. Correlations between cow effects for ECM yield and ALLDIS as well as METAB differed not significantly from 0 (data not shown).
Figure 7 and 8 illustrate Pearson correlation coefficients between cow effects for EB and disease categories for both breeds. Correlations were almost completely negative in $\mathrm{GH}$, ranging from -0.15 to 0.05 . In $\mathrm{GH}$, correlations different from $0(P<0.05)$ occurred for MAST between DIM 157 and 207, for CLAW between DIM 10 and 56 and DIM 164 and 268, for METAB between DIM 3 and 40, and for ALLDIS up to DIM 59 and between DIM 108 and 269. In FV, correlations between cow effects for EB and disease categories ranged from -0.25 to 0.18. Correlations for MAST differed from $0(P<0.05)$ between DIM 245 and 298. For CLAW correlations different from $0(P<0.05)$ occurred up to DIM 44, for METAB up to DIM 10, and for ALLDIS up to DIM 44 as well as between DIM 267 and 301.

\section{DISCUSSION}

Dairy cow diseases influence farm profitability and animal welfare negatively (Broom and Corke, 2002; Liang et al., 2017). Furthermore, DMI affects total milk production costs strongly by feed costs and is important for dairy cow efficiency (Hemme et al., 2014; VandeHaar et al., 2016). This study evaluated health data of GH and FV dairy cows aggregated to 4 disease categories: MAST, CLAW, METAB, and ALLDIS. Estimated Pearson correlation coefficients between cow effects for disease categories and DMI as well as EB were mostly negative $(P<0.05)$, especially in early

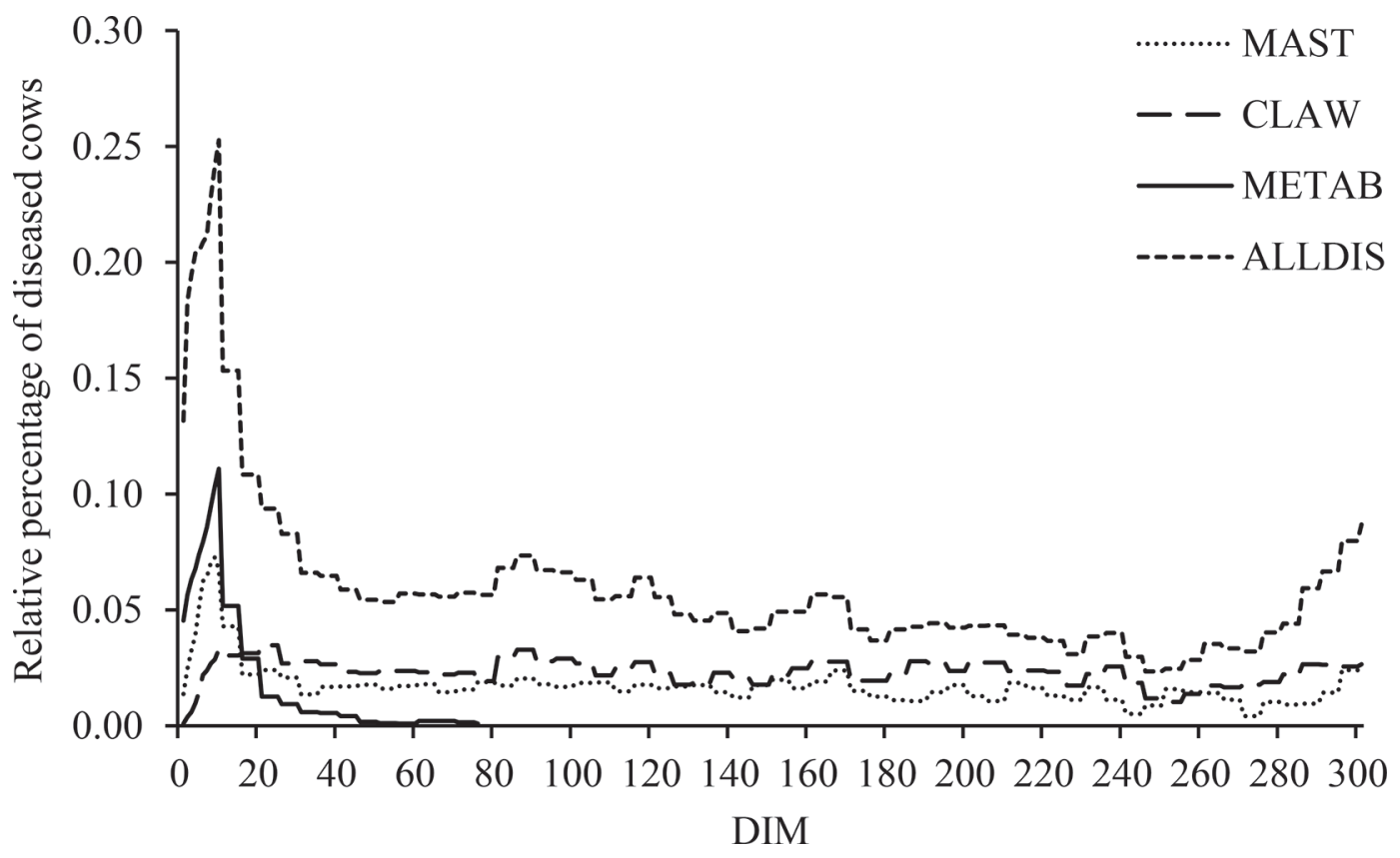

Figure 1. Relative percentage of diseased cows per DIM for mastitis (MAST), claw and leg diseases (CLAW), metabolic diseases (METAB), and all diseases (ALLDIS) in German Holstein dairy cows. 
Table 6. Relative percentage (LSM $\pm \mathrm{SE}$ ) of diseased cows for 4 disease categories within lactation and difference of the means (of the underlying liability scale) in German Holstein and Fleckvieh dairy cows

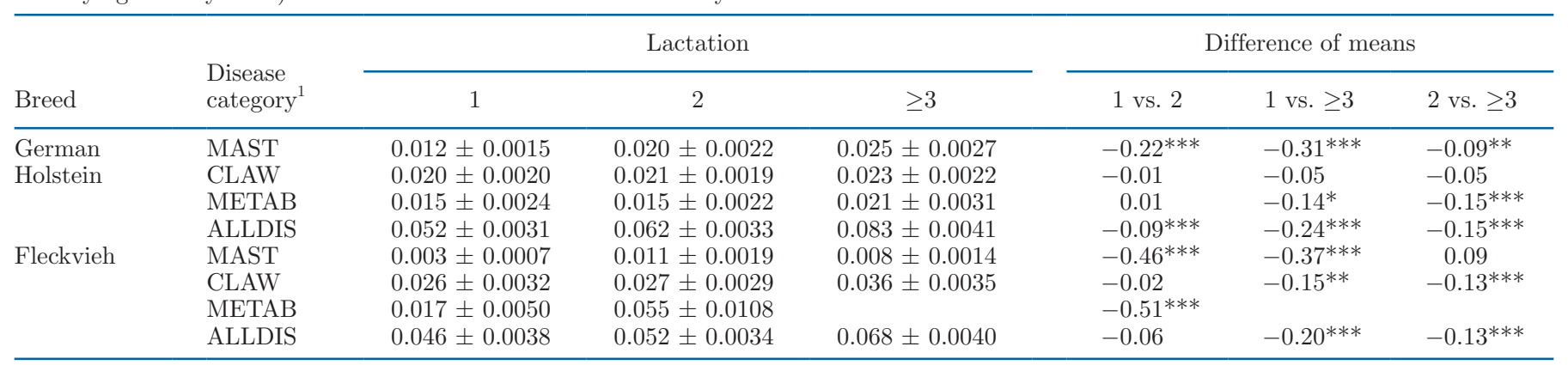

${ }^{1}$ MAST $=$ mastitis, CLAW $=$ claw and leg diseases, METAB $=$ metabolic diseases, ALLDIS $=$ all diseases.

${ }^{*} P<0.05,{ }^{* *} P<0.01,{ }^{* * *} P<0.001$.

lactation. If genetic relationships are similar to these phenotypic relationships, breeding for more efficient dairy cows through savings in DMI could be questioned because a low DMI, especially in early lactation, is correlated with an increased liability to diseases (Ingvartsen, 2006; Pérez-Báez et al., 2019).

Gernand et al. (2012) investigated health data of Holstein cows in Germany, which were recorded over a period of $2 \mathrm{yr}$. Health data included in their categories were similar to our disease categories. In their study, percentages of lactations with at least 1 treatment were $38.0 \%$ for mastitis, $22.6 \%$ for claw disorders, and $7.8 \%$ for metabolism. In a study of Holstein cows in Canada, Collard et al. (2000) indicated a lactational incidence of
$35.0 \%$ for mastitis and $67.8 \%$ for all diseases. There are several reasons why comparing percentages of diseased cows or treated lactations across studies is difficult. On the one hand, data quality varies between farms and even within farm over time for reasons such as people recording data with different ability to recognize diseases, different prophylactic farm management, or different diets between farms (Rauw et al., 1998; Miglior et al., 2013). Therefore, editing heterogeneous producer-recorded health data is an important step before further analyses of diseases (Miglior et al., 2013). On the other hand, studies differ in their disease diagnosing, categorizing, and recording (e.g., first or every treatment) next to often different data (e.g., observed

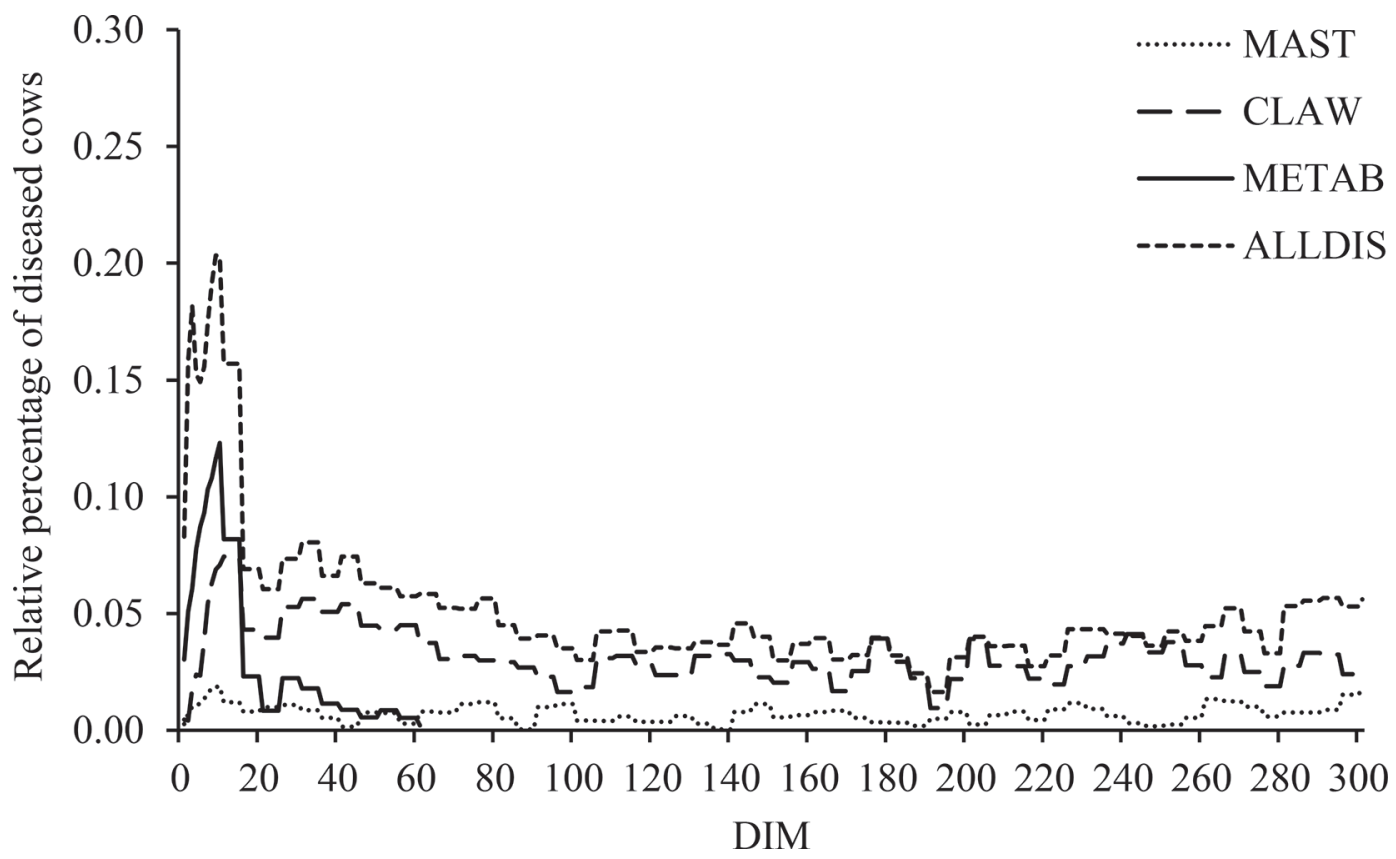

Figure 2. Relative percentage of diseased cows per DIM for mastitis (MAST), claw and leg diseases (CLAW), metabolic diseases (METAB), and all diseases (ALLDIS) in Fleckvieh dairy cows. 


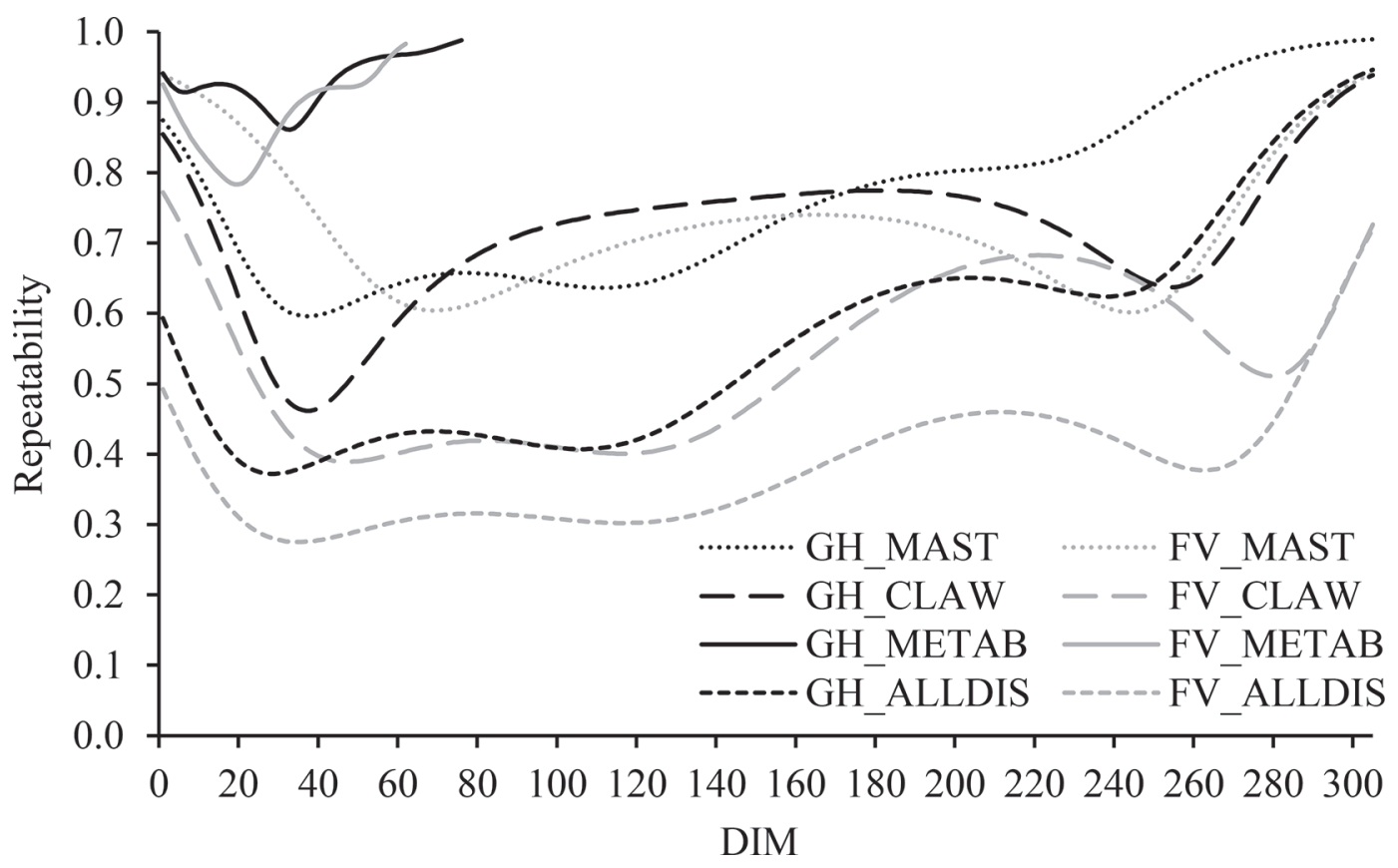

Figure 3. Repeatability of mastitis (MAST), claw and leg diseases (CLAW), metabolic diseases (METAB), and all diseases (ALLDIS) plotted against DIM in German Holstein (GH; black) and Fleckvieh (FV; gray) dairy cows.

lactation stages) and binary trait definitions (e.g., assigning a disease period, adding sick days, defining a new disease period; Kelton et al., 1998; Sogstad et al., 2005a; Buttchereit et al., 2012). In addition, diseases and calculation of percentage of diseased cows are not defined uniformly. The latter may be reported as incidence or prevalence (Kelton et al., 1998). Instead of this, we present percentages of affected cow days and relative percentages of diseased cows per DIM to account for the disease intensity throughout lactation.

Data recording in early lactation, especially in the first 20 DIM, is important to investigate dairy cow diseases (Hinrichs et al., 2005; Buttchereit et al., 2012) because most diseases such as MAST and METAB are more frequent in early lactation (e.g., Zwald et al., 2004; Gernand et al., 2012; Koeck et al., 2012). Claw diseases also occur depending on lactation stage (Sogstad et al., 2005b) but in most studies, as in ours, CLAW appeared relatively constant throughout lactation (Figures 1 and 2 ). This can be explained by the fact that a disease category and no single diseases has been analyzed because of too low frequencies. Furthermore, percentage of diseased cows could be biased by regular hoof trimming management based on cow individual lactation stages because more claw diseases are discovered during hoof trimming (Buttchereit et al., 2012).

Generally, multiparous cows are more affected due to diseases than primiparous cows because they have a reduced disease resistance (Pryce et al., 1999; Kadarmideen et al., 2000; Abdelsayed et al., 2017). This is also evident from the relative percentages of diseased cows in our study (Table 6).

Using random regressions in threshold models for binary coded disease categories may cause convergence problems. We initially tried to model e.g., herd-testdays or herd-test-weeks instead of herd-years and to nest DIM within lactation, but this failed due to extreme categories without diseased days (Harville and Mee, 1984).

High repeatability assesses that the accuracy and consistency of phenotypic measurements are high. The results show estimated repeatability of binary data on the link scale that should be similar to estimates on the original scale. Nonetheless, estimates on the link scale can be slightly higher than estimates on the original scale (Nakagawa and Schielzeth, 2010). In addition, it is well known that repeatability based on threshold models is higher compared with estimates based on linear models (Kadarmideen et al., 2000). Repeatability of ALLDIS varied from 0.37 to 0.95 in $\mathrm{GH}$ and from 0.28 to 0.72 in FV. Heterogenic diseases included in the disease category ALLDIS could have contribute to the fact that this disease category has the lowest repeatability.

Repeatability represents the upper limit of trait heritability (Visscher et al., 2008). Generally, disease heritabilities are low (Zwald et al., 2004; Heringstad et 


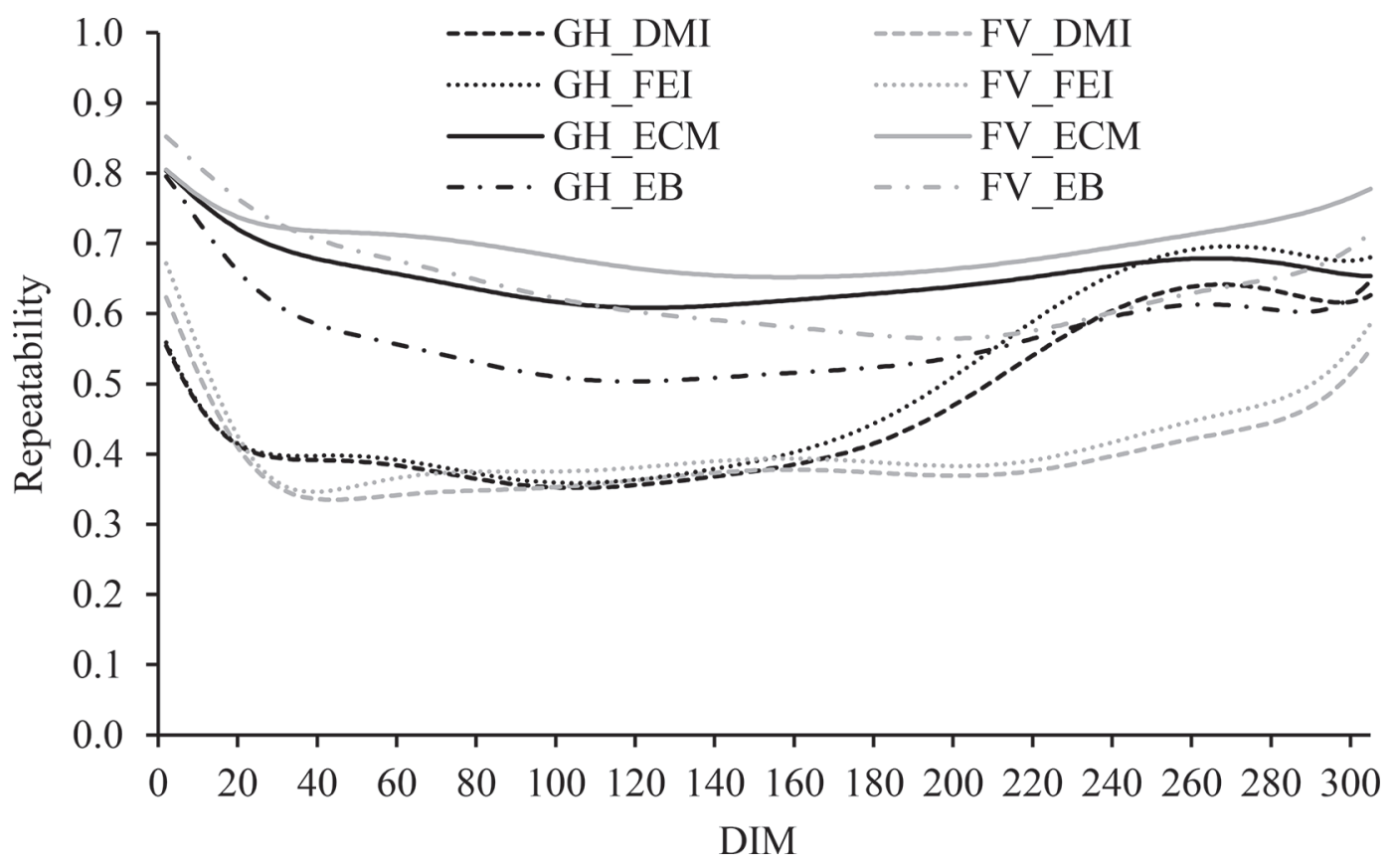

Figure 4. Repeatability of DMI, feed energy intake (FEI), ECM yield, and energy balance (EB) plotted against DIM in German Holstein (GH; black) and Fleckvieh (FV; gray) dairy cows.

al., 2005). Therefore, we expected lower repeatability for disease categories. Our estimated repeatability was often high, especially for METAB, which could be due to high genetic or high permanent environmental effects in the between-cow variance of repeatability estimates. Abdelsayed et al. (2017) mentioned that genetic is the predominant source of cow variance in diseases. However, shorter lactation stage and more sick days could contribute to a high between-cow variance and therefore to a higher repeatability for METAB. A limitation of this study is that no pedigree information was included and therefore no partition into additive genetic variance and permanent environmental variance to estimate heritabilities could be performed.
Repeatabilities for ECM yield were almost constant during lactation. They ranged from 0.61 to 0.80 in GH and from 0.65 to 0.81 in FV. Harder et al. (2019) stated already that routine milk performance testing and standardized measurements of milk ingredients in GH and FV research farms led to similar repeatabilities for ECM yield in GH and FV cows.

Concordant repeatabilities for DMI and FEI could be due to similar energy contents in the rations of research farms. Repeatabilities for DMI showed different progressions in GH and FV throughout lactation but a similar range. In GH, repeatability for DMI ranged from 0.35 to 0.64 and from 0.33 to 0.62 in FV. This concludes with Tetens et al. (2014). Harder et al. (2019) explained

Table 7. Correlations between cow effects of selected DIM for all diseases in German Holstein (above the diagonal) and Fleckvieh (below the diagonal) dairy cows

\begin{tabular}{|c|c|c|c|c|c|c|c|c|c|c|c|}
\hline DIM & 5 & 35 & 65 & 95 & 125 & 155 & 185 & 215 & 245 & 275 & 305 \\
\hline 35 & 0.61 & & 0.85 & 0.62 & 0.22 & -0.12 & -0.27 & -0.30 & -0.12 & 0.22 & 0.37 \\
\hline 65 & 0.09 & 0.83 & & 0.90 & 0.51 & 0.05 & -0.21 & -0.32 & -0.23 & 0.13 & 0.33 \\
\hline 125 & -0.18 & 0.31 & 0.65 & 0.88 & & 0.87 & 0.68 & 0.48 & 0.15 & -0.26 & -0.37 \\
\hline 155 & -0.09 & -0.01 & 0.24 & 0.55 & 0.87 & & 0.95 & 0.82 & 0.40 & -0.29 & -0.57 \\
\hline 185 & 0.02 & -0.22 & -0.09 & 0.22 & 0.64 & 0.93 & & 0.95 & 0.59 & -0.17 & -0.54 \\
\hline 275 & 0.05 & -0.12 & -0.20 & -0.21 & -0.15 & -0.01 & 0.15 & 0.35 & 0.67 & & 0.91 \\
\hline 305 & -0.11 & 0.17 & 0.16 & -0.02 & -0.30 & -0.48 & -0.50 & -0.37 & -0.03 & 0.72 & \\
\hline
\end{tabular}


Table 8. Correlations between cow effects of selected DIM for metabolic diseases in German Holstein (above the diagonal) and Fleckvieh (below the diagonal) dairy cows

\begin{tabular}{lrcccccrr}
\hline DIM & 5 & 15 & 25 & 35 & 45 & 55 & \multicolumn{1}{c}{65} & \multicolumn{1}{c}{75} \\
\hline 5 & & 0.71 & 0.48 & 0.14 & -0.11 & -0.10 & 0.05 & 0.28 \\
15 & 0.70 & & 0.91 & 0.31 & -0.31 & -0.45 & -0.27 & 0.24 \\
25 & 0.17 & 0.65 & & 0.63 & -0.01 & -0.23 & -0.19 & 0.13 \\
35 & -0.08 & 0.16 & 0.83 & & 0.76 & 0.53 & 0.32 & -0.01 \\
45 & -0.08 & 0.01 & 0.62 & 0.92 & & 0.94 & 0.69 & 0.02 \\
55 & 0.11 & 0.12 & 0.18 & 0.30 & 0.60 & & 0.87 & 0.24 \\
65 & & & & & & & & 0.69 \\
75 & & & & & & & & \\
\hline
\end{tabular}

different repeatability's level for DMI between GH and $\mathrm{FV}$ with different measurement techniques.

All repeatability's curves declined toward mid-lactation and increased again in late lactation. This agrees with Buttchereit et al. (2010), even if their repeatabilities for EB were lower; they ranged from about 0.40 to 0.60 in the first 180 DIM.

Heringstad et al. (2003) concluded that liability to mastitis is genetically not the same trait during lactation. Our results indicate generally higher correlations between cow effects for adjacent lactation stages than for more distant lactation stages. Furthermore, repeatability for disease categories fluctuated strongly throughout lactation. Consequently, we assume that disease categories were not the same trait during lactation.
Little has been reported on the correlations between DMI or FEI and liability to diseases in literature. Søndergaard et al. (2002) estimated negative phenotypic and genetic correlations between feed intake capacity (ratio of average daily DMI to BW) and SCC as an information trait for mastitis $(-0.12 ;-0.10 \pm$ $0.29)$, as well as mastitis treatments $(-0.09 ;-0.35$ $\pm 0.50)$. In our study, estimated Pearson correlation coefficients were negative especially between cow effects for DMI and ALLDIS. They ranged from -0.31 to -0.27 in $\mathrm{GH}$ and from -0.42 to -0.34 in $\mathrm{FV}$ in the first 20 DIM. According to this, we hypothesize that cows with lower DMI have a higher liability to diseases primarily in early lactation. A reason might be the fact that cows are in negative EB during this lactation stage.

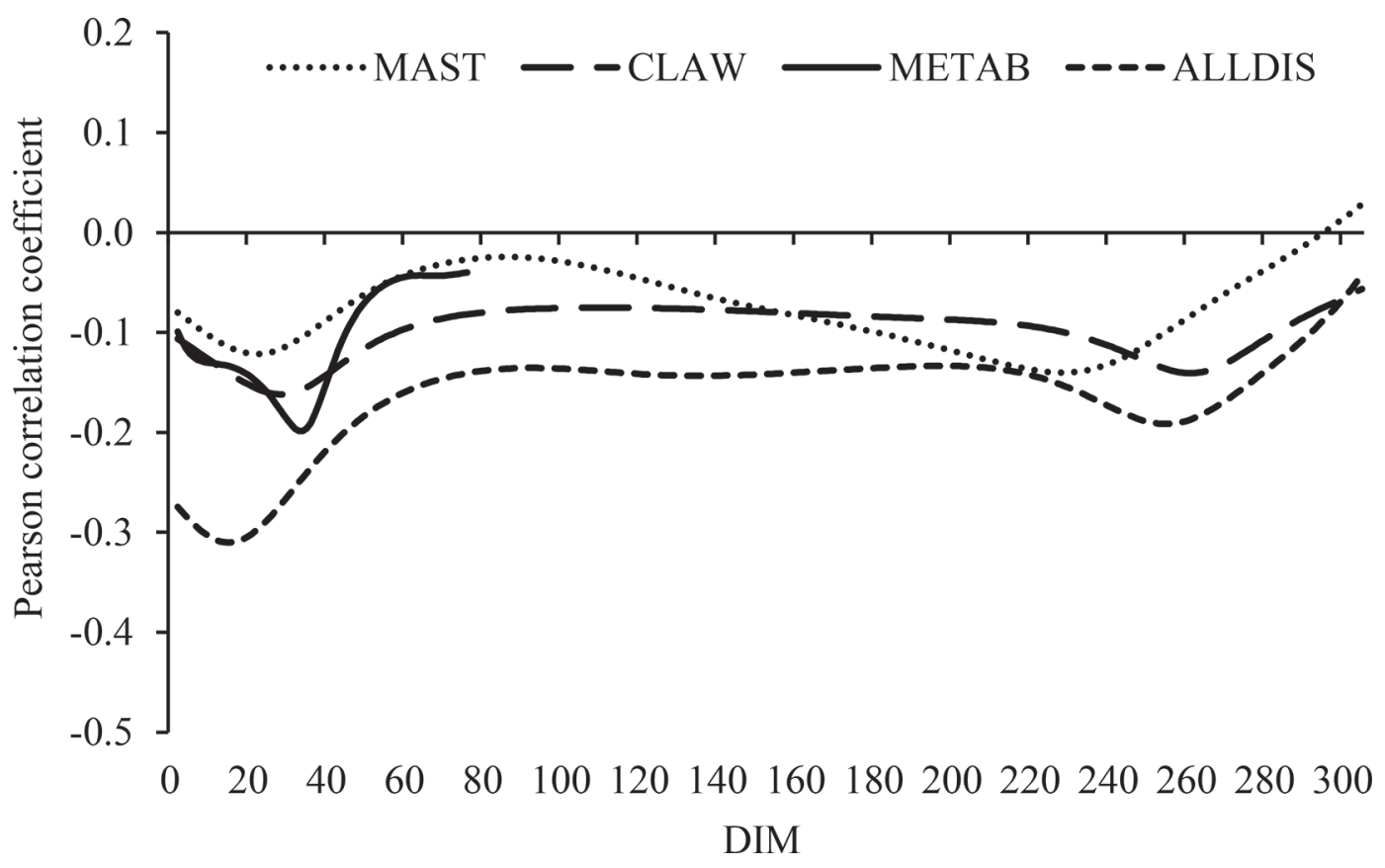

Figure 5. Correlation between cow effects for DMI and 4 disease categories (MAST $=$ mastitis, CLAW $=$ claw and leg diseases, METAB $=$ metabolic diseases, ALLDIS = all diseases) plotted against DIM in German Holstein dairy cows (DIM 2-305: $\mathrm{n}=1,312 ;$ DIM 2-76: $\mathrm{n}=1,144$; SE: MAST 0.027-0.028, CLAW 0.027-0.028, METAB 0.028-0.030, ALLDIS 0.025-0.028). 


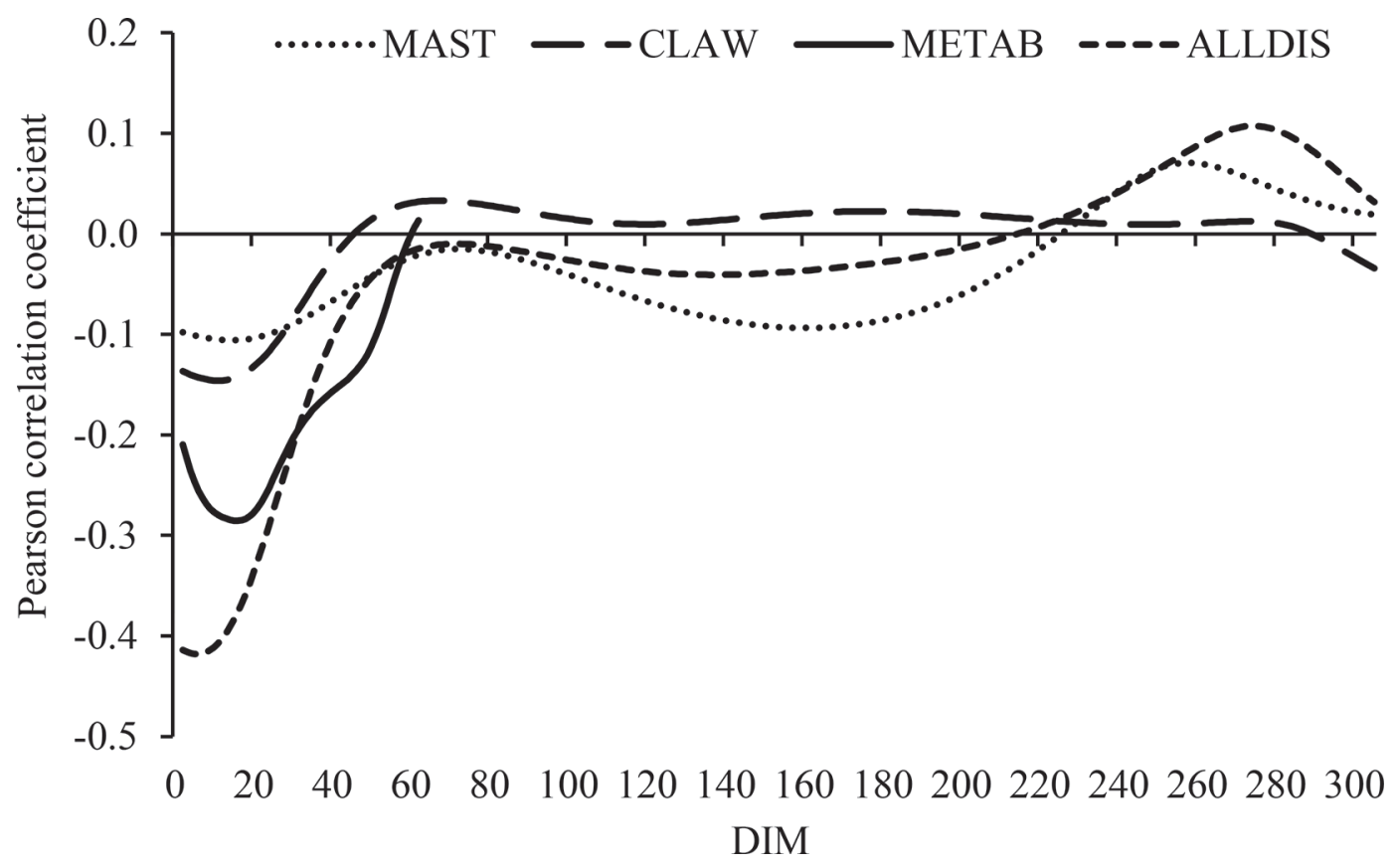

Figure 6. Correlation between cow effects for DMI and 4 disease categories (MAST $=$ mastitis, CLAW $=$ claw and leg diseases, METAB $=$ metabolic diseases, ALLDIS = all diseases) plotted against DIM in Fleckvieh dairy cows (DIM 2-305: $\mathrm{n}=286 ;$ DIM 2-62: $\mathrm{n}=207 ;$ SE: MAST 0.058-0.059, CLAW 0.057-0.059, METAB 0.062-0.070, ALLDIS 0.047-0.059).

The dual-purpose breed FV had a lower ECM yield than GH. However, the Pearson correlation coefficients between cow effects for ECM yield and disease cat- egories differed rarely between $\mathrm{GH}$ and FV because both were mostly not significant different from 0 . In comparison, Kadarmideen et al. (2000) estimated low

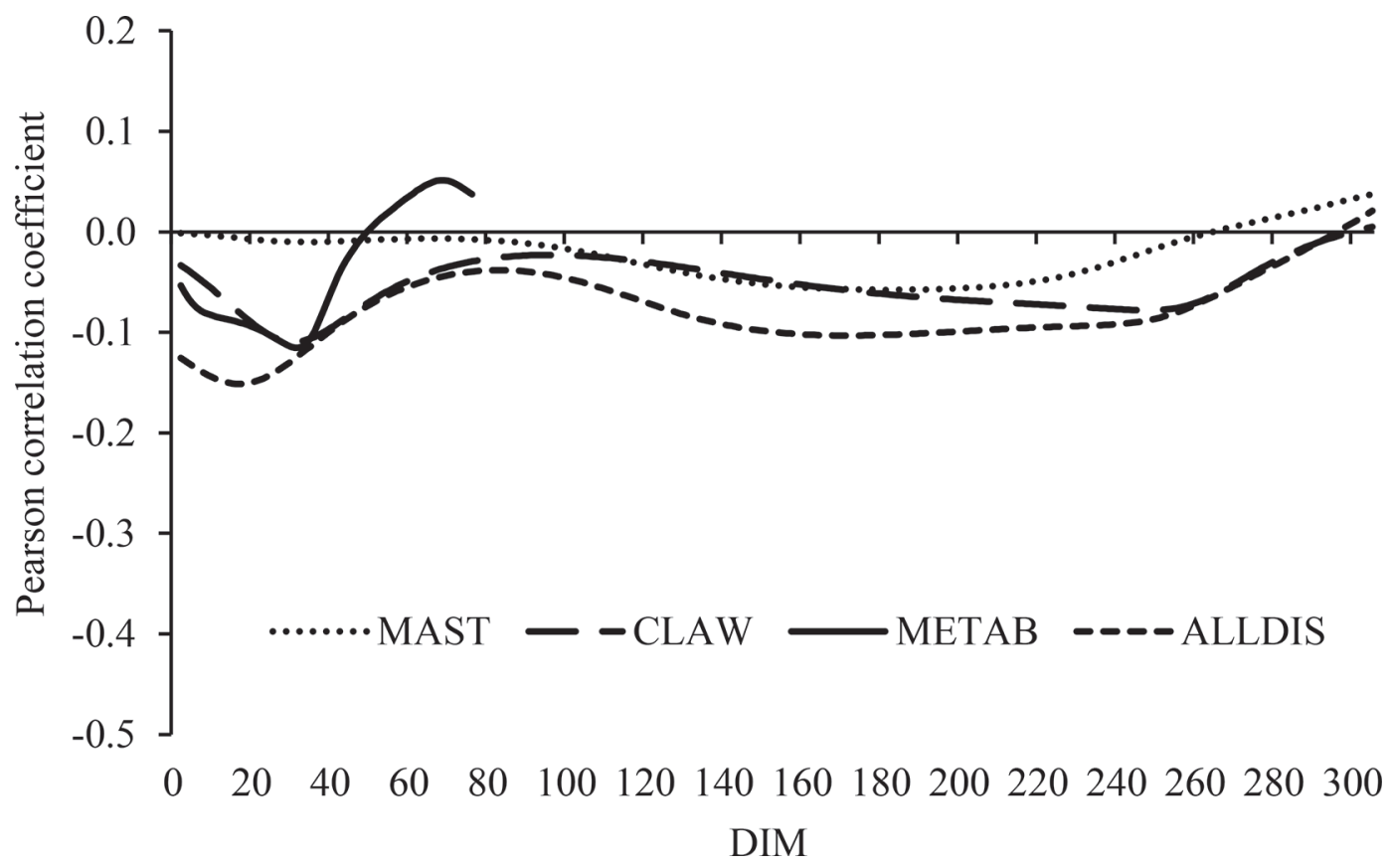

Figure 7. Correlation between cow effects for energy balance and 4 disease categories (MAST = mastitis, CLAW $=$ claw and leg diseases, METAB = metabolic diseases, ALLDIS = all diseases) plotted against DIM in German Holstein dairy cows (DIM 2-305: $\mathrm{n}=1,304$; DIM 2-76: $\mathrm{n}=1,113$; SE: MAST 0.028, CLAW 0.027-0.028, METAB 0.029-0.030, ALLDIS 0.027-0.028). 


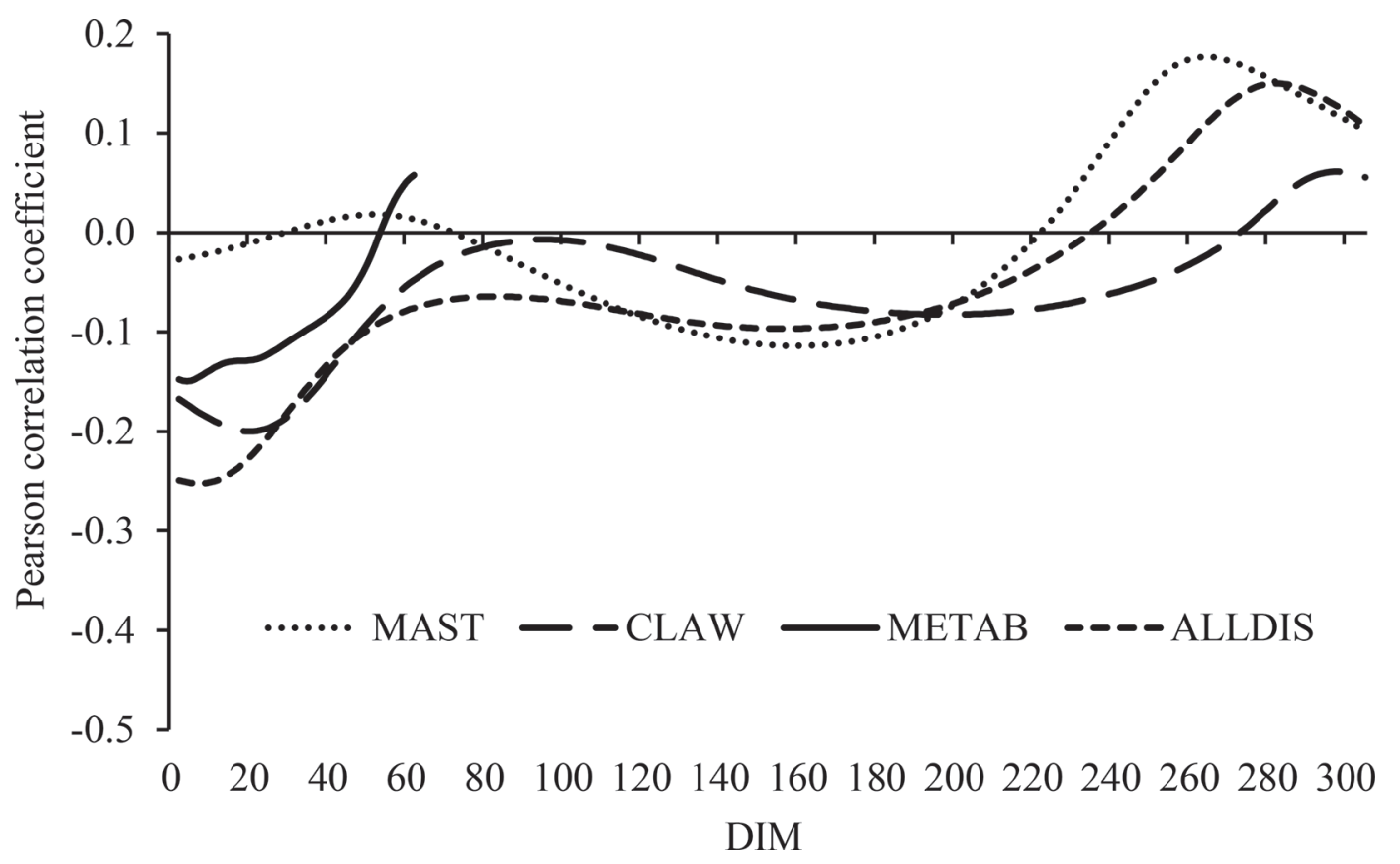

Figure 8. Correlation between cow effects for energy balance and 4 disease categories (MAST $=$ mastitis, CLAW $=$ claw and leg diseases, METAB $=$ metabolic diseases, ALLDIS $=$ all diseases $)$ plotted against DIM in Fleckvieh dairy cows $($ DIM 2-305: $\mathrm{n}=286 ;$ DIM 2-62: $\mathrm{n}=205$; SE: MAST 0.056-0.059, CLAW 0.056-0.059, METAB 0.067-0.070, ALLDIS 0.054-0.059).

positive phenotypic correlations between 305-d milk yield and diseases.

An unfavorable genetic relationship between high milk yield as well as negative EB and liability to diseases is unquestionable (Rauw et al., 1998; Kadarmideen et al., 2000; Buttchereit et al., 2012). Buttchereit et al. (2012) estimated a genetic correlation between EB and mastitis of -0.58 and between EB and claw and leg diseases of -0.23 in primiparous cows. In our study, Pearson correlation coefficients between cow effects for $\mathrm{EB}$ and MAST ranged from -0.06 to 0.04 in $\mathrm{GH}$ and from -0.11 to 0.18 in FV. Between cow effects for EB and CLAW, correlations varied from -0.11 to 0.00 in $\mathrm{GH}$ and from -0.20 to 0.06 in FV. In FV, correlations in late lactation increased strongly into positive values. This might be due to the decreasing number of observations in late lactation, which limits the interpretation of these values.

Factors that influence EB directly are milk yield and DMI. Consequently, there are lactation stages, during which a low DMI reduces EB and has a negative effect on health (Collard et al., 2000; Pérez-Báez et al., 2019). Subsequently, a higher DMI implies a less pronounced negative EB and can have a positive effect on health especially in early lactation (Van Arendonk et al., 1991; Veerkamp, 1998; Veerkamp et al., 2013). In this study, Pearson correlation coefficients between cow effects for
DMI were higher than correlation coefficients between cow effects for EB and liability to diseases. In addition, calculations of EB based on estimates for energy requirements that assumed to be equal for both breeds. However, cow effect correlations between DMI and EB were much lower in FV than in GH. They were on average 0.64 in GH and 0.33 in FV. Consequently, DMI could be more suitable to assess liability to diseases.

Søndergaard et al. (2002) concluded that cows with a high daily energy intake have phenotypically and genetically a low feed efficiency. Therefore, reducing DMI could improve efficiency but we regard this strategy without consideration of lactation stage with caution because of the negative relationship between DMI and liability to diseases. In terms of efficiency, we want to note that DMI in early lactation is genetically low correlated with DMI in late lactation. Different genes affect DMI at different lactation stages (Berry et al., 2007; Tetens et al., 2014; Harder et al., 2020). Spurlock et al. (2012) concluded this for EB as well. In the future specific selection for DMI within lactation stage could be used, and this might reduce the conflict between high efficiency and high DMI of dairy cows (Tetens et al., 2014). It should be also noted, that in an energetic system, as a dairy cow, energy could only change from one form to another (Rauw and Gomez-Raya, 2015). Therefore, breeding for efficiency could be limited by 
dairy cow nutrient demand in early lactation to stay healthy over the whole lactation. A high-energy supply is also relevant for animal welfare (Rauw and GomezRaya, 2015).

\section{CONCLUSIONS}

This study assesses comprehensively relationships between DMI as well as EB and liability to diseases with longitudinal phenotypic data. Repeatabilities were promising throughout lactation. Results illustrate that cow effect correlations between DMI and disease categories are mostly negative, especially in early lactation. In the last decades, functional traits were included in breeding goals, and health, fertility, and longevity got more attention. Future breeding for efficiency should not act against this positive progress. High DMI is important to avoid strong negative EB in early lactation due to high enough energy supply. Furthermore, this could contribute to stable health and thus to keep the so far inestimably energy requirement of the immune system low. In a following study of a larger data set, genetic relationships between DMI as well as EB and liability to diseases should be analyzed to allow more precise genetic parameters.

\section{ACKNOWLEDGMENTS}

We gratefully acknowledge financial support for the project eMissionCow that is supported by funds of the German Government's Special Purpose Fund held at Landwirtschaftliche Rentenbank (Frankfurt am Main, Germany). We thank for data provided from the project optiKuh that was supported by funds from the Federal Ministry of Food and Agriculture (BMEL; Bonn, Germany), based on a decision of the Parliament of the Federal Republic of Germany via the Federal Office for Agriculture and Food (BLE), under the Innovation Support Program. Furthermore, we thank staff on the dairy research farms and project partners for data collection for many years. The authors have not stated any conflicts of interest.

\section{REFERENCES}

Abdelsayed, M., M. Haile-Mariam, and J. E. Pryce. 2017. Genetic parameters for health traits using data collected from genomic information nucleus herds. J. Dairy Sci. 100:9643-9655. https:// doi.org/10.3168/jds.2017-12960.

Ali, T. E., and L. R. Schaeffer. 1987. Accounting for covariances among test day milk yields in dairy cows. Can. J. Anim. Sci. 67:637-644. https://doi.org/10.4141/cjas87-067.

Berry, D. P., and J. J. Crowley. 2013. Cell biology symposium: Genetics of feed efficiency in dairy and beef cattle. J. Anim. Sci. 91:1594-1613. https://doi.org/10.2527/jas.2012-5862.
Berry, D. P., B. Horan, M. O'Donovan, F. Buckley, E. Kennedy, M. McEvoy, and P. Dillon. 2007. Genetics of grass dry matter intake, energy balance, and digestibility in grazing Irish dairy cows. J. Dairy Sci. 90:4835-4845. https://doi.org/10.3168/jds.2007-0116.

Berry, D. P., and J. E. Pryce. 2014. Feed efficiency in growing and mature animals. In Proceedings, 10th World Congress of Genetics Applied to Livestock Production, Vancouver, Canada. American Society of Animal Science, Champaign, IL.

Boichard, D., and M. Brochard. 2012. New phenotypes for new breeding goals in dairy cattle. Animal 6:544-550. https://doi.org/10 $.1017 /$ S1751731112000018.

Broom, D. M., and M. J. Corke. 2002. Effects of disease on farm animal welfare. Acta Vet. Brno 71:133-136. https://doi.org/10.2754/ avb200271010133.

Burnham, K. P., and D. R. Anderson. 1998. Model Selection and Inference: A Practical Information-Theoretic Approach. Springer, New York, NY.

Buttchereit, N., E. Stamer, W. Junge, and G. Thaller. 2010. Evaluation of five lactation curve models fitted for fat:protein ratio of milk and daily energy balance. J. Dairy Sci. 93:1702-1712. https:/ /doi.org/10.3168/jds.2009-2198.

Buttchereit, N., E. Stamer, W. Junge, and G. Thaller. 2012. Genetic parameters for energy balance, fat/protein ratio, body condition score and disease traits in German Holstein cows. J. Anim. Breed. Genet. 129:280-288. https://doi.org/10.1111/j.1439-0388.2011 .00976.x.

Carlén, E., K. Grandinson, U. Emanuelson, and E. Strandberg. 2009. Random regression models for genetic evaluation of clinical mastitis in dairy cattle. Animal 3:1100-1108. https://doi.org/10.1017/ S1751731109004601.

Collard, B. L., P. J. Boettcher, J. C. M. Dekkers, D. Petitclerc, and L. R. Schaeffer. 2000. Relationships between energy balance and health traits of dairy cattle in early lactation. J. Dairy Sci. 83:2683-2690. https://doi.org/10.3168/jds.S0022-0302(00)75162 -9 .

Connor, E. E. 2015. Invited review: Improving feed efficiency in dairy production: Challenges and possibilities. Animal 9:395-408. https: //doi.org/10.1017/S1751731114002997.

de Haas, Y., J. E. Pryce, M. P. L. Calus, E. Wall, D. P. Berry, P. Løvendahl, N. Krattenmacher, F. Miglior, K. Weigel, D. Spurlock, K. A. Macdonald, B. Hulsegge, and R. F. Veerkamp. 2015. Genomic prediction of dry matter intake in dairy cattle from an international data set consisting of research herds in Europe, North America, and Australasia. J. Dairy Sci. 98:6522-6534. https://doi .org/10.3168/jds.2014-9257.

Esposito, G., P. C. Irons, E. C. Webb, and A. Chapwanya. 2014. Interactions between negative energy balance, metabolic diseases, uterine health and immune response in transition dairy cows. Anim. Reprod. Sci. 144:60-71. https://doi.org/10.1016/j.anireprosci.2013 .11.007.

Friggens, N. C., P. Berg, P. Theilgaard, I. R. Korsgaard, K. L. Ingvartsen, P. Løvendahl, and J. Jensen. 2007. Breed and parity effects on energy balance profiles through lactation: Evidence of genetically driven body energy change. J. Dairy Sci. 90:5291-5305. https: //doi.org/10.3168/jds.2007-0173.

Gernand, E., P. Rehbein, U. U. von Borstel, and S. König. 2012. Incidences of and genetic parameters for mastitis, claw disorders, and common health traits recorded in dairy cattle contract herds. J. Dairy Sci. 95:2144-2156. https://doi.org/10.3168/jds.2011-4812.

Gianola, D. 1982. Theory and analysis of threshold characters. J. Anim. Sci. 54:1079-1096. https://doi.org/10.2527/jas1982.5451079x.

GKUH. 2019. GKUH Gesundheitsmonitoring Standards. Accessed Nov. 12, 2019. http://www.gkuh.de/Texte/procedure_recording2 .html.

Goff, J. P., and R. L. Horst. 1997. Physiological changes at parturition and their relationship to metabolic disorders. J. Dairy Sci. 80:1260-1268. https://doi.org/10.3168/jds.S0022-0302(97)76055 -7 .

Harder, I., E. Stamer, W. Junge, and G. Thaller. 2019. Lactation curves and model evaluation for feed intake and energy balance in 
dairy cows. J. Dairy Sci. 102:7204-7216. https://doi.org/10.3168/ jds.2018-15300.

Harder, I., E. Stamer, W. Junge, and G. Thaller. 2020. Estimation of genetic parameters and breeding values for feed intake and energy balance using pedigree relationships or single-step genomic evaluation in Holstein Friesian cows. J. Dairy Sci. 103:2498-2513. https: //doi.org/10.3168/jds.2019-16855.

Harville, D. A., and R. W. Mee. 1984. A mixed-model procedure for analyzing ordered categorical data. Biometrics 40:393-408. https:/ /doi.org/10.2307/2531393.

Hemme, T., M. M. Uddin, and O. A. Ndambi. 2014. Benchmarking cost of milk production in 46 countries. J. Rev. Glob. Econ. 3:254270. https://doi.org/10.6000/1929-7092.2014.03.20.

Heringstad, B., Y. M. Chang, D. Gianola, and G. Klemetsdal. 2003. Genetic analysis of longitudinal trajectory of clinical mastitis in first-lactation Norwegian cattle. J. Dairy Sci. 86:2676-2683. https: //doi.org/10.3168/jds.S0022-0302(03)73863-6.

Heringstad, B., Y. M. Chang, D. Gianola, and G. Klemetsdal. 2005. Genetic analysis of clinical mastitis, milk fever, ketosis, and retained placenta in three lactations of Norwegian Red cows. J. Dairy Sci. 88:3273-3281. https://doi.org/10.3168/jds.S0022 -0302(05)73010-1.

Hinrichs, D., E. Stamer, W. Junge, and E. Kalm. 2005. Genetic analyses of mastitis data using animal threshold models and genetic correlation with production traits. J. Dairy Sci. 88:2260-2268. https: //doi.org/10.3168/jds.S0022-0302(05)72902-7.

Hurley, A. M., N. Lopez-Villalobos, S. McParland, E. Lewis, E. Kennedy, M. O'Donovan, J. L. Burke, and D. P. Berry. 2018. Characteristics of feed efficiency within and across lactation in dairy cows and the effect of genetic selection. J. Dairy Sci. 101:1267-1280. https://doi.org/10.3168/jds.2017-12841.

Ingvartsen, K. L. 2006. Feeding- and management-related diseases in the transition cow: Physiological adaptations around calving and strategies to reduce feeding-related diseases. Anim. Feed Sci. Technol. 126:175-213. https://doi.org/10.1016/j.anifeedsci.2005 .08.003.

Kadarmideen, H. N., R. Thompson, and G. Simm. 2000. Linear and threshold model genetic parameters for disease, fertility and milk production in dairy cattle. Anim. Sci. 71:411-419. https://doi.org/ 10.1017/S1357729800055338.

Kelton, D. F., K. D. Lissemore, and R. E. Martin. 1998. Recommendations for recording and calculating the incidence of selected clinical diseases of dairy cattle. J. Dairy Sci. 81:2502-2509. https://doi .org/10.3168/jds.S0022-0302(98)70142-0.

Kirchgeßner, M., G. I. Stangl, F. J. Schwarz, F. X. Roth, K.-H. Südekum, and K. Eder. 2014. Tierernährung: Leitfaden für Studium, Beratung und Praxis. 14th ed. DLG-Verlag, Frankfurt am Main, Germany.

Kirkpatrick, M., D. Lofsvold, and M. Bulmer. 1990. Analysis of the inheritance, selection and evolution of growth trajectories. Genetics 124:979-993.

Koeck, A., F. Miglior, D. F. Kelton, and F. S. Schenkel. 2012. Health recording in Canadian Holsteins: Data and genetic parameters. J. Dairy Sci. 95:4099-4108. https://doi.org/10.3168/jds.2011-5127.

Ledinek, M., L. Gruber, F. Steininger, B. Fuerst-Waltl, K. Zottl, M. Royer, K. Krimberger, M. Mayerhofer, and C. Egger-Danner. 2019. Analysis of lactating cows in commercial Austrian dairy farms: Interrelationships between different efficiency and production traits, body condition score and energy balance. Ital. J. Anim. Sci. 18:723-733. https://doi.org/10.1080/1828051X.2019.1569485.

Liang, D., L. M. Arnold, C. J. Stowe, R. J. Harmon, and J. M. Bewley. 2017. Estimating US dairy clinical disease costs with a stochastic simulation model. J. Dairy Sci. 100:1472-1486. https://doi.org/10 $.3168 /$ jds.2016-11565.

Littell, R. C., G. A. Milliken, W. W. Stroup, R. D. Wolfinger, and O. Schabenberger. 2006. SAS for Mixed Models. 2nd ed. SAS Institute Inc., Cary, NC.

Luo, M. F., P. J. Boettcher, L. R. Schaeffer, and J. C. M. Dekkers. 2001. Bayesian inference for categorical traits with an application to variance component estimation. J. Dairy Sci. 84:694-704. https: //doi.org/10.3168/jds.S0022-0302(01)74524-9.

Miglior, F., A. Koeck, D. F. Kelton, and F. S. Schenkel. 2013. Comparison of different methods to validate a dataset with producerrecorded health events. Pages 109-116 in Proc. of the ICAR Conf., ICAR technical series no. 17. Challenges and benefits of health data recording in the context of food chain quality, management and breeding, Aarhus, Denmark.

Moreno, C., D. Sorensen, L. A. García-Cortés, L. Varona, and J. Altarriba. 1997. On biased inferences about variance components in the binary threshold model. Genet. Sel. Evol. 29:145-160. https:// doi.org/10.1186/1297-9686-29-2-145.

Nakagawa, S., and H. Schielzeth. 2010. Repeatability for Gaussian and non-Gaussian data: A practical guide for biologists. Biol. Rev. Camb. Philos. Soc. 85:935-956. https://doi.org/10.1111/j.1469 $-185 X .2010 .00141 . \mathrm{X}$.

Neuenschwander, T. F.-O., F. Miglior, J. Jamrozik, O. Berke, D. F. Kelton, and L. R. Schaeffer. 2012. Genetic parameters for producer-recorded health data in Canadian Holstein cattle. Animal 6:571-578. https://doi.org/10.1017/S1751731111002059.

Pérez-Báez, J., C. A. Risco, R. C. Chebel, G. C. Gomes, L. F. Greco, S. Tao, I. M. Thompson, B. C. do Amaral, M. G. Zenobi, N. Martinez, C. R. Staples, G. E. Dahl, J. A. Hernández, J. E. P. Santos, and K. N. Galvão. 2019. Association of dry matter intake and energy balance prepartum and postpartum with health disorders postpartum: Part II. Ketosis and clinical mastitis. J. Dairy Sci. 102:9151-9164. https://doi.org/10.3168/jds.2018-15879.

Pryce, J. E., B. L. Nielsen, R. F. Veerkamp, and G. Simm. 1999. Genotype and feeding system effects and interactions for health and fertility traits in dairy cattle. Livest. Prod. Sci. 57:193-201. https: //doi.org/10.1016/S0301-6226(98)00180-8.

Rauw, W. M., and L. Gomez-Raya. 2015. Genotype by environment interaction and breeding for robustness in livestock. Front. Genet. 6:310. https://doi.org/10.3389/fgene.2015.00310.

Rauw, W. M., E. Kanis, E. N. Noordhuizen-Stassen, and F. J. Grommers. 1998. Undesirable side effects of selection for high production efficiency in farm animals: A review. Livest. Prod. Sci. 56:1533. https://doi.org/10.1016/S0301-6226(98)00147-X.

SAS Institute Inc. 2013. SAS/STAT 13.1 User's guide. SAS Institute Inc., Cary, NC.

Sauvant, D. 2019. Modeling efficiency and robustness in ruminants: The nutritional point of view. Anim. Front. 9:60-67. https://doi .org/10.1093/af/vfz012.

Schaeffer, L. R. 2004. Application of random regression models in animal breeding. Livest. Prod. Sci. 86:35-45. https://doi.org/10 .1016/S0301-6226(03)00151-9.

Schwarz, G. 1978. Estimating the dimension of a model. Ann. Stat. 6:461-464. https://doi.org/10.1214/aos/1176344136.

Sogstad, Å. M., T. Fjeldaas, and O. Østerås. 2005b. Lameness and claw lesions of the Norwegian Red dairy cattle housed in free stalls in relation to environment, parity and stage of lactation. Acta Vet. Scand. 46:203-217. https://doi.org/10.1186/1751-0147-46-203.

Sogstad, Å. M., T. Fjeldaas, O. Østerås, and K. P. Forshell. 2005a. Prevalence of claw lesions in Norwegian dairy cattle housed in tie stalls and free stalls. Prev. Vet. Med. 70:191-209. https://doi.org/ 10.1016/j.prevetmed.2005.03.005.

Søndergaard, E., M. K. Sørensen, I. L. Mao, and J. Jensen. 2002. Genetic parameters of production, feed intake, body weight, body composition, and udder health in lactating dairy cows. Livest. Prod. Sci. 77:23-34. https://doi.org/10.1016/S0301-6226(02)00023 -4 .

Spurlock, D. M., J. C. M. Dekkers, R. Fernando, D. A. Koltes, and A. Wolc. 2012. Genetic parameters for energy balance, feed efficiency, and related traits in Holstein cattle. J. Dairy Sci. 95:5393-5402. https://doi.org/10.3168/jds.2012-5407.

Swalve, H. H. 2000. Theoretical basis and computational methods for different test-day genetic evaluation methods. J. Dairy Sci. 83:1115-1124. https://doi.org/10.3168/jds.S0022-0302(00)74977 -0 . 
Tetens, J., G. Thaller, and N. Krattenmacher. 2014. Genetic and genomic dissection of dry matter intake at different lactation stages in primiparous Holstein cows. J. Dairy Sci. 97:520-531. https://doi .org/10.3168/jds.2013-7301.

Van Arendonk, J. A. M., G. J. Nieuwhof, H. Vos, and S. Korver. 1991. Genetic aspects of feed intake and efficiency in lactating dairy heifers. Livest. Prod. Sci. 29:263-275. https://doi.org/10.1016/0301 $-6226(91) 90103-W$.

VandeHaar, M. J., L. E. Armentano, K. Weigel, D. M. Spurlock, R. J. Tempelman, and R. Veerkamp. 2016. Harnessing the genetics of the modern dairy cow to continue improvements in feed efficiency. J. Dairy Sci. 99:4941-4954. https://doi.org/10.3168/jds .2015-10352.

Veerkamp, R. F. 1998. Selection for economic efficiency of dairy cattle using information on live weight and feed intake: A review. J. Dairy Sci. 81:1109-1119. https://doi.org/10.3168/jds.S0022 -0302(98)75673-5.

Veerkamp, R. F., J. E. Pryce, D. Spurlock, D. Berry, M. Coffey, P. Løvendahl, R. van der Linde, J. Bryant, F. Miglior, Z. Wang, M.
Winters, N. Krattenmacher, N. Charfeddine, J. Pedersen, and Y. de Haas. 2013. Selection on feed intake or feed efficiency: A position paper from gDMI breeding goal discussions. Interbull Bull. $47: 15-22$.

Visscher, P. M., W. G. Hill, and N. R. Wray. 2008. Heritability in the genomics era-Concepts and misconceptions. Nat. Rev. Genet. 9:255-266. https://doi.org/10.1038/nrg2322.

Zwald, N. R., K. A. Weigel, Y. M. Chang, R. D. Welper, and J. S. Clay. 2004. Genetic selection for health traits using producerrecorded data. I. Incidence rates, heritability estimates, and sire breeding values. J. Dairy Sci. 87:4287-4294. https://doi.org/10 .3168/jds.S0022-0302(04)73573-0.

\section{ORCIDS}

V. A. E. Becker (ํ) https://orcid.org/0000-0002-0096-1237 